\title{
Evaluación de la contaminación microbiológica en los equipos radiográficos de una clínica dental privada
}

\author{
Evaluation of microbiological contamination on radiographic equipment in a private dental clinic \\ Luis Paipay Santos ${ }^{1, a}$, Víctor Calderón Ubaqui ${ }^{2, b}$, Dora Maurtua Torres ${ }^{3, c}$, Ruth Cristóbal Delgado ${ }^{3, c}$
}

\section{RESUMEN}

Objetivo: Determinar la presencia de bacterias y hongos en las superficies contactadas por el operador durante la toma de radiografías intraorales en el cuarto de toma y caja de procesado de los módulos de la Clínica Dental de la Facultad de Estomatología, Universidad Peruana Cayetano Heredia. Material y Métodos: Se tomaron muestras de 6 superficies contactadas durante la toma y revelado de radiografías en 5 días al azar y no consecutivos, usando una plantilla estéril de $25 \mathrm{~cm}^{2}$ y un hisopo estéril con caldo tripticasa de soya y otro con agua destilada. Se utilizaron diferentes medios de cultivos para el aislamiento. La identificación fue a través de pruebas bioquímicas. Resultados: Se encontró una concentración bacteriana variada en todas las superficies radiográficas. Además se encontraron microorganismos comensales y patógenos, los más prevalentes fueron los bacilos gram negativos (Pseudomona stutzeri) y con menor frecuencia los cocos gram positivos (Enterococcus faecalis). Conclusiones: Los resultados obtenidos destacan la necesidad de adecuar la infraestructura o evaluar las normas de limpieza y desinfección aplicadas e implementar programas de monitoreo, para disminuir el riesgo de adquirir infecciones en la práctica radiográfica.

PALABRAS CLAVE: Bacteria, micología, control de infección, radiografía dental, microbiología. (Fuente: DeCS BIREME)

\section{SUMMARY}

Objectives: The purpose of this study was to assess the presence of bacteria and fungi during radiographic exposure and processing in high-touch areas in the dental x-ray devices from of the School of Dentistry at Universidad Peruana Cayetano Heredia. Methods: Samples from six surfaces contacted were collected during

Facultad de Estomatología Roberto Beltrán, Universidad Peruana Cayetano Heredia. Lima, Perú.

Asociación Peruana de Radiología Bucal y Maxilofacial. Lima, Perú.

Facultad de Ciencias y Filosofía Alberto Cazorla Talleri, Universidad Peruana Cayetano Heredia. Lima, Perú.

Cirujano Dentista.

Especialista en Radiología Oral y Maxilofacial.

Magister en Ciencias con mención en Microbiología. 
radiographic exposure and processing in five days at random and nonconsecutive, using a sterile sampling template in $25 \mathrm{~cm}^{2}$ and sterile swab with tryptic soy broth and other with distilled water. Different culture media were used for the isolation. The identification was through biochemical tests. Results: Bacterial concentration varied in all radiographic surfaces was found. Besides commensal and pathogenic microorganisms were found, were the most prevalent gram negative bacilli (Pseudomona stutzeri) and less frequently gram positive cocci (Enterococcus faecalis). Conclusions: The results highlight the need to adequate infrastructure or to evaluate standards of cleaning and disinfection applied and implements monitoring programs to decrease the risk of acquiring infections in radiographic practice.

\section{KEYWORDS: Bacteria, mycology, infection control, dental radiography, microbiology. (Source: MeSH NLM)}

\section{INTRODUCCIÓN}

Las radiografías dentales son una herramienta útil y necesaria para el diagnóstico y tratamiento de las enfermedades bucales. Generalmente, el procedimiento de tomar una radiografía no es considerado invasivo; sin embargo, siempre existe un riesgo de contaminación cruzada entre pacientes y/o dentista con la saliva ya que ésta alberga una amplia gama de microorganismos como lo demuestran White y Glaze (1). Además, en ocasiones la rigidez de la película radiográfica produce laceraciones en la mucosa de la cavidad bucal mezclando la saliva con sangre. Sin embargo, la infección también puede trasmitirse por la contaminación de superficies y equipos (2).

El control de infección en odontología es un importante tema que ha tomado mucha importancia en años recientes y los protocolos establecidos para la prevención de una contaminación cruzada son prácticas comunes aplicadas en muchos países. Sin embargo, por múltiples factores, la aplicación de estas medidas no se realiza. Las escuelas dentales han sido alertadas y el control de infección se ha convertido en una parte esencial de su currícula.

Katz y col. (1989) observaron que muchas escuelas dentales desinfectaban sólo el tubo de rayos $\mathrm{X}$ en el área radiológica (3).

Cada consultorio dental, debe tener una política escrita que describa las prácticas de control de infecciones, es mejor si una persona de la práctica clínica, por lo general el dentista, asume la responsabilidad de la aplicación de este procedimiento.

Para prevenir o reducir el riesgo de infecciones, la Asociación Dental Americana (ADA) y el Centro de
Control y Prevención de Enfermedades han publicado protocolos para el control de infecciones, que son aplicables a todos los servicios radiográficos (4). Sin embargo, el empleo de estos medios y medidas en el área de radiología dental no se efectúa rigurosamente por diversos factores, principalmente económico. Además, se han realizado pocas investigaciones que evalúen el grado de contaminación en radiología dental. Por otro lado, no existen mecanismos que controlen la ejecución de estos protocolos, ni normas internas que regulen dicha actividad.

El objetivo del presente estudio fue determinar la presencia de bacterias y hongos en las superficies contactadas por el operador durante la toma de radiografías intraorales en el cuarto de toma y sistema de revelado de los módulos de pregrado del primer y segundo piso de la Clínica Dental de la Facultad de Estomatología Roberto Beltrán, Universidad Peruana Cayetano Heredia (UPCH).

\section{MATERIAL Y MÉTODOS}

Se evaluaron en total 6 cuartos de toma radiográfica y 4 cajas de revelado manual de los módulos de pregrado de la Clínica Dental. Seis superficies que frecuentemente fueron contactadas por el operador durante la toma radiográfica y revelado manual fueron seleccionadas, siendo éstas: 4 superficies correspondientes al cuarto de toma radiográfica (cabezal de rayos $\mathrm{X}$, mandil plomado, disparador $\mathrm{y}$ perilla externa de la puerta) y 2 superficies de la sala de revelado (manga y tapa de la caja), siendo en total 36 superficies.

\section{Recolección de muestra}

Para la recolección de las muestras se utilizó la técnica de hisopado empleado en los estudios de Da Silva y col. (5) el 2004 y Lee (6) el 2010. Las muestras 

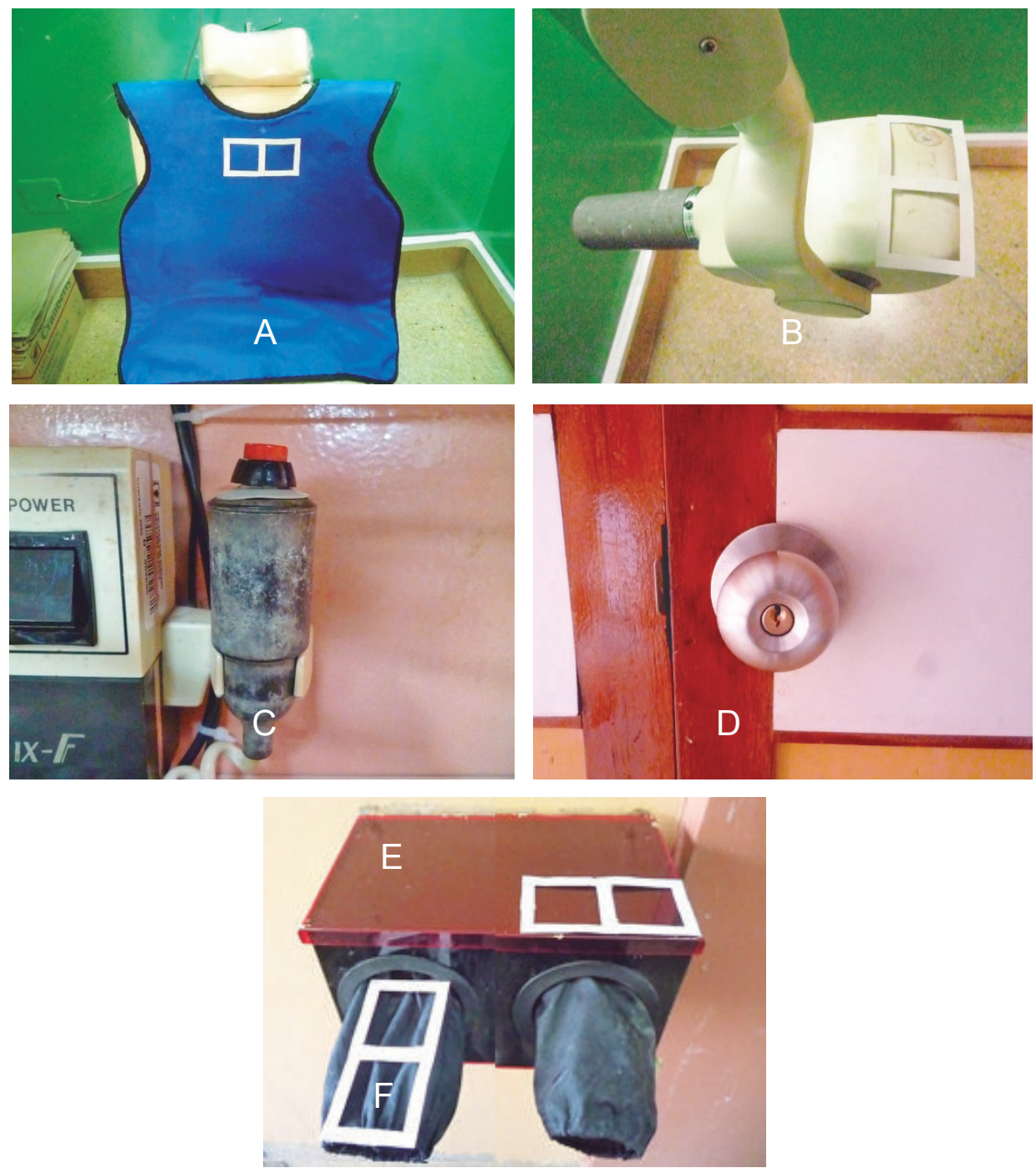

Figura 1. Superficies del cuarto de toma radiográfica y del área de revelado de los módulos de la Clínica Dental. A: Mandil plomado. B: Cabezal de rayos X. C: Disparador. D: Perilla externa de la puerta. E: Caja de revelado. F: Manga de tela.

fueron siempre obtenidas por el mismo operador 30 minutos después de finalizadas las actividades clínicas (6:30 p.m.) en 5 días escogidos al azar y no consecutivos. Para este propósito se confeccionó una plantilla con un área abierta de $25 \mathrm{~cm}^{2}$ en base a la guía técnica para el análisis microbiológico de alimentos y bebidas (7). Esta plantilla estéril se utilizó en todas las superficies, excepto en el disparador y la perilla. Se empleó un hisopo estéril para $1 \mathrm{ml}$ de caldo tripticasa de soya (TSB) y otro para $1 \mathrm{ml}$ de agua destilada estéril. Previo al hisopado, se colocaron las plantillas en la parte central de la superficie, sólo en la tapa de la caja de revelado dichas plantillas fueron colocadas en la esquina inferior. Seguidamente, ambos hisopos se humedecieron y frotaron sobre cada una de las superficies seleccionadas, la muestra recogida se mantuvo en el tubo de ensayo. Luego, las muestras fueron llevadas al Laboratorio de Bacteriología de la Facultad de Ciencias Alberto Cazorla Talleri, de la UPCH para la inoculación e incubación.

\section{Inoculación e incubación}

Cada una de las muestras se homogenizó en un agitador Vortex durante 1 minuto. Las muestras homogeneizadas se sembraron en 5 medios diferentes para investigar el crecimiento de diferentes tipos de microorganismos: Agar Plate Count (PC), Agar Sabouraud con cloranfenicol (SC), Agar sangre (AS), Agar cetrimide (AC) y Agar Mc Conkey (MC). 
De las muestras del tubo que contenía el hisopo con caldo TSB (muestra directa), se tomó $0,1 \mathrm{ml}$ y se pasó a otro tubo con $0,9 \mathrm{ml}$ de TSB (dilución $10^{-1}$ ). De ambos tubos se tomó $0,1 \mathrm{ml}$ y se sembraron en el agar plate count mediante la técnica de dispersión. La muestra con agua destilada estéril no se diluyó, se tomó $0,1 \mathrm{ml}$ y se sembró en agar sabouraud con cloranfenicol empleando la misma técnica. Asimismo, de la muestra directa de caldo TSB se tomó una asada y sembró por agotamiento en el AS, AC y MC.

Las placas con agar PC, AC y MC fueron incubadas a $37^{\circ} \mathrm{C}$ por 48 horas. El AS fue colocado en una jarra y bajo condiciones de microaerofilia e incubado a $37^{\circ} \mathrm{C}$ por 48 horas. El agar SC fue incubado a $20^{\circ} \mathrm{C}$ por 5 días.

Después de la incubación se procedió a realizar el conteo de colonias de la dilución $\left(10^{-1}\right)$ del agar plate count.

\section{Identificación de microorganismos}

Las colonias bacterianas que crecieron en AS y MC fueron nuevamente cultivadas en agar cerebro corazón (BHA) y agar tripticasa de soya (TSA) respectivamente, cada siembra se incubó bajo las mismas condiciones mencionadas anteriormente. Tras el aislamiento, las colonias se sometieron a las pruebas de catalasa, oxidasa y tinción Gram. Además se realizaron pruebas bioquímicas convencionales y sólo en el caso de los bacilos gram negativos no fermentadores se empleó el API 20NE.
Para la identificación de hongos, se separaron levaduras de hongos filamentosos. En el caso del hongo filamentoso, éste fue cultivado nuevamente de forma individual en el SC por punción e incubado a temperatura ambiental por 3 días. Transcurrido el tiempo, se identificó mediante la observación macroscópica de la colonia y tinción con $\mathrm{KOH} \mathrm{10 \% .}$ Para la identificación de la levadura, se sembró por agotamiento en un nuevo SC y se utilizó la tinción Gram, la prueba de tubo germinativo y asimilación de carbohidratos.

Un mismo operador fue el encargado de realizar las lecturas de todas las pruebas bioquímicas.

\section{RESULTADOS}

El recuento de Unidades Formadoras de Colonias (UFC) por superficie y módulo se realizó a partir de la dilución de $10^{-1} \mathrm{y}$ se presenta en la tabla 1 . Entre las superficies evaluadas, el mandil plomado y la caja de revelado mostraron el más alto grado de contaminación, seguido del cabezal de rayos X, disparador, perilla de la puerta y la manga de la caja de revelado. En el análisis estadístico se observó que las superficies del segundo piso de la Clínica Dental presentaron un promedio superior de colonias, excepto en la manga de tela. Además se observó diferencia estadísticamente significativa sólo entre el primer y segundo piso, en lo referente a los cabezales de rayos $X(p>0,05)($ Tabla 2$)$.

Tabla 1. Recuento de UFC a partir de la dilución por superficie y módulo.

\begin{tabular}{ccccccc}
\hline & \multicolumn{3}{c}{ PRIMER PISO } & & \multicolumn{2}{c}{ SEGUNDO PISO } \\
& MÓDULO 1 & MÓDULO 2 & MÓDULO 3 & MÓDULO 4 & MÓDULO 5 & MÓDULO 6 \\
\hline Cabezal & $4 \times 10^{2}$ & $4 \times 10^{2}$ & $3 \times 10^{2}$ & $14 \times 10^{2}$ & $18 \times 10^{2}$ & $242 \times 10^{2}$ \\
Mandil & $25 \times 10^{2}$ & $3 \times 10^{2}$ & $2 \times 10^{2}$ & $362 \times 10^{2}$ & $245 \times 10^{2}$ & $14 \times 10^{2}$ \\
Disparador & $2 \times 10^{2}$ & $19 \times 10^{2}$ & $3 \times 10^{2}$ & $9 \times 10^{2}$ & $5 \times 10^{2}$ & $26 \times 10^{2}$ \\
Perilla & $8 \times 10^{2}$ & $8 \times 10^{2}$ & $4 \times 10^{2}$ & $4 \times 10^{2}$ & $7 \times 10^{2}$ & $12 \times 10^{2}$ \\
$\begin{array}{c}\text { Caja de } \\
\text { revelado }\end{array}$ & $5 \times 10^{2}$ & $134 \times 10^{2}$ & $14 \times 10^{2}$ & $7 \times 10^{2}$ & $10^{2}$ & $221 \times 10^{2}$ \\
$\begin{array}{l}\text { Manga de tela } \\
\text { Todos los valores de UFC están expresados en UFC/cm }{ }^{2}\end{array}$ & $2 \times 10^{2}$ & $7 \times 10^{2}$ & $5 \times 10^{2}$ & $2 \times 10^{2}$ & $2 \times 10^{2}$ & $3 \times 10^{2}$ \\
\hline
\end{tabular}


Los microorganismos que presentaron un constante crecimiento fueron Pseudomonas stutzeri y Enterococcus faecalis. Otras especies bacterianas encontradas con menor frecuencia fueron del género Staphylococcus, S. epidermidis. Además, en una superficie (cabezal de rayos X) fue posible identificar $S$. aureus. Asimismo, dentro de los bacilos gram negativos, se hallaron diversas especies y algunas de éstas representan un alto riesgo de patogenicidad como son Pseudomona aeruginosa, Klebsiella pneumoniae, Burkholderia cepacia y Acinetobacter baumannii (Tabla 3 ).

Con respecto a los hongos, los más predominantes fueron los hongos filamentosos, de la especie Aspergillus flavus. Otros hongos encontrados fueron: Penicillium spp., Curvularia spp., Ulocladium spp., Aureobasidium pullulans y Fusarium spp. La única levadura aislada fue Candida albicans del cabezal de rayos X. Asimismo, se aprecia que en la perilla de la puerta y en el módulo 5 no hubo crecimiento de hongos (Tabla 4).

\section{DISCUSIÓN}

En la actualidad el control de infecciones en odontología es un problema político, social y económico, ya que conlleva a un aumento en los costos, procesos y vigilancia para realizar atención de salud aplicando los protocolos internacionales establecidos, realizar estudios de investigación y la preparación de profesionales, técnicos, personal administrativo y de limpieza.

Las superficies radiográficas analizadas presentaron un alto nivel de contaminación (2-207 UFC), un valor similar encontrado por Ezoddini y col. (8) cuando evaluaron las superficies radiográficas

Tabla 2. Comparación de UFC entre las superficies de muestra de los módulos correspondientes a cada piso.

\begin{tabular}{|c|c|c|c|c|c|c|}
\hline Partes & Piso & Media & Desv. típ. & Mínimo & Máximo & Sig. \\
\hline \multirow[b]{2}{*}{ Cabezal } & Primer Piso & 3,67 & 0,577 & 3,00 & 4,00 & \multirow[b]{2}{*}{0,046} \\
\hline & Segundo Piso & 91,33 & 130,496 & 14,00 & 242,00 & \\
\hline \multirow[b]{2}{*}{ Mandil } & Primer Piso & 10,00 & 13,000 & 2,00 & 25,00 & \multirow[b]{2}{*}{$0,127^{\natural}$} \\
\hline & Segundo Piso & 207,00 & 177,085 & 14,00 & 362,00 & \\
\hline \multirow[b]{2}{*}{ Disparador } & Primer Piso & 8,00 & 9,539 & 2,00 & 19,00 & \multirow[b]{2}{*}{0,563} \\
\hline & Segundo Piso & 13,33 & 11,150 & 5,00 & 26,00 & \\
\hline \multirow{2}{*}{ Perilla } & Primer Piso & 6,67 & 2,309 & 4,00 & 8,00 & \multirow{2}{*}{1,000} \\
\hline & Segundo Piso & 7,67 & 4,041 & 4,00 & 12,00 & \\
\hline \multirow[b]{2}{*}{ Caja } & Primer Piso & 51,00 & 72,021 & 5,00 & 134,00 & \multirow[b]{2}{*}{0,827} \\
\hline & Segundo Piso & 79,33 & 122,696 & 7,00 & 221,00 & \\
\hline \multirow[b]{2}{*}{ Manga } & Primer Piso & 4,67 & 2,517 & 2,00 & 7,00 & \multirow[b]{2}{*}{0,246} \\
\hline & Segundo Piso & 2,33 & 0,577 & 2,00 & 3,00 & \\
\hline
\end{tabular}

aPrueba U de Mann Whitney

'Prueba T para muestras independientes 
Tabla 3. Bacterias por superficie y módulo.

\begin{tabular}{|c|c|c|c|c|c|c|}
\hline & MÓDULO 1 & MÓDULO 2 & MÓDULO 3 & MÓDULO 4 & MÓDULO 5 & MÓDULO 6 \\
\hline \multirow{4}{*}{$\begin{array}{l}\text { Cabezal de } \\
\text { rayos x }\end{array}$} & & \multirow{4}{*}{ Ulocladium spp. } & \multirow{4}{*}{ Candida albicans } & & & Aspergillus flavus \\
\hline & & & & & & Aspergillus fumigatus \\
\hline & & & & & & Curvularia spp. \\
\hline & & & & & & Ulocladium spp. \\
\hline & & & & & & Penicillium spp. \\
\hline $\begin{array}{l}\text { Mandil } \\
\text { plomado }\end{array}$ & -- & --- & ---------------- & ---------------- & --------------- & Aureobasidium \\
\hline & & & & & & pullulans \\
\hline Disparador & ----------------- & ----------------- & ---------------- & ---- & ---- & A. flavus \\
\hline Caja de revelado & A. flavus & ------------- & ---------------- & ----------------- & ---- & ---------------- \\
\hline Manga de tela & ---------------' & ---------------- & ---------------- & Fusarium spp. & ---------------- & ---------------- \\
\hline
\end{tabular}

En negrita: Hongos que representan un alto riesgo de infección cruzada.

Tabla 4. Hongos por superficie y módulo.

\begin{tabular}{|c|c|c|c|c|c|c|}
\hline & MODULO 1 & MODULO 2 & MODULO 3 & MODULO 4 & MODULO 5 & MODULO 6 \\
\hline $\begin{array}{c}\text { Cabezal de } \\
\text { rayos X }\end{array}$ & $\begin{array}{c}\text { Staphylococcus } \\
\text { epidermidis } \\
\text { Enterococcusfaecalis } \\
\text { Pseudomona } \\
\text { aeruginosa }\end{array}$ & $\begin{array}{c}\text { E. faecalis } \\
\text { Staphylococcus } \\
\text { schleiferi } \\
\text { Pseudomona } \\
\text { putida }\end{array}$ & $\begin{array}{c}\text { S. epidermidis } \\
\text { Acinetobacter } \\
\text { baumannii }\end{array}$ & $\begin{array}{c}\text { S. epidermidis } \\
\text { S. } \\
\text { saprophyticus } \\
\text { A. baumannii }\end{array}$ & $\begin{array}{c}\text { E. faecalis } \\
\text { Pseudomonastutzeri }\end{array}$ & $\begin{array}{c}\text { Micrococcus spp. } \\
\text { S. schleiferi } \\
\text { Staphylococcus } \\
\text { aureus } \\
\text { E. faecalis } \\
\text { Klebsiella } \\
\text { pneumoniae } \\
\text { Brevibacterium } \\
\text { luteolum }\end{array}$ \\
\hline $\begin{array}{c}\text { Mandil } \\
\text { plomado }\end{array}$ & $\begin{array}{c}\text { E. faecalis } \\
\text { K. pneumoniae } \\
\text { Burkholderia } \\
\text { cepacia }\end{array}$ & $\begin{array}{l}\text { S. epidermidis } \\
\text { S. saprophyticus }\end{array}$ & E. faecalis & $\begin{array}{c}\text { S. epidermidis } \\
\text { E. faecalis } \\
\text { Eikenella } \\
\text { corrodens } \\
\text { Neisseria spp. }\end{array}$ & $\begin{array}{c}\text { E. faecalis } \\
\text { Moraxella lincolnii } \\
\text { Neisseria spp. }\end{array}$ & $\begin{array}{l}\text { S. saprophyticus } \\
\text { E. faecalis } \\
\text { Bacillus mycoides } \\
\text { Bacillus cereus }\end{array}$ \\
\hline Disparador & $\begin{array}{l}\text { S. saprophyticus } \\
\text { E. faecalis }\end{array}$ & $\begin{array}{l}\text { S. epidermidis } \\
\text { E. faecalis } \\
\text { B. cereus } \\
\text { P. aeruginosa }\end{array}$ & $\begin{array}{c}S . \\
\text { saprophyticus }\end{array}$ & $\begin{array}{c}\text { Pseudomona } \\
\text { luteola } \\
\text { P. stutzeri }\end{array}$ & E. faecalis & $\begin{array}{c}\text { Brevibacillus } \\
\text { brevis } \\
\text { K. pneumoniae }\end{array}$ \\
\hline $\begin{array}{l}\text { Perilla de } \\
\text { puerta }\end{array}$ & $\begin{array}{c}\text { Micrococcus spp. } \\
\text { S. epidermidis } \\
\text { S. saprophyticus } \\
\text { E. faecalis } \\
\text { P. putida }\end{array}$ & $\begin{array}{c}\text { Micrococcus } \\
\text { spp. } \\
\text { S. saprophyticus } \\
\text { P. stutzeri } \\
\text { P. luteola }\end{array}$ & P. stutzeri & $\begin{array}{c}\text { P. stutzeri } \\
\text { Pseudomona } \\
\text { oryzihabitans }\end{array}$ & $\begin{array}{l}\text { P. luteola } \\
\text { B. cepacia }\end{array}$ & $\begin{array}{c}\text { P. luteola } \\
\text { P. stutzeri } \\
\text { P. putida } \\
\text { Enterobacter } \\
\text { aglomerans }\end{array}$ \\
\hline $\begin{array}{l}\text { Caja de } \\
\text { revelado }\end{array}$ & $\begin{array}{c}\text { E. faecalis } \\
\text { Listeria innocua } \\
\text { P. aeruginosa }\end{array}$ & $\begin{array}{c}\text { E. faecalis } \\
\text { Streptococcus } \\
\text { mutans } \\
\text { B. cereus }\end{array}$ & $\begin{array}{c}\text { S. epidermidis } \\
\text { E. faecalis } \\
\text { P. stutzeri }\end{array}$ & $\begin{array}{l}\text { S. epidermidis } \\
\text { E. faecalis }\end{array}$ & A. baumannii & $\begin{array}{l}\text { S. epidermidis } \\
\text { S. saprophyticus } \\
\text { E. faecalis } \\
\text { S. mutans } \\
\text { Streptococcus } \\
\text { constellatus } \\
\text { L. innocua } \\
\text { P. stutzeri }\end{array}$ \\
\hline $\begin{array}{l}\text { Manga de } \\
\text { tela }\end{array}$ & $\begin{array}{l}\text { P. putida } \\
\text { P. luteola }\end{array}$ & $\begin{array}{l}\text { S. epidermidis } \\
\text { S. schleiferi } \\
\text { P. putida }\end{array}$ & B. cepacia & S. epidermidis & S. epidermidis & P. stutzeri \\
\hline
\end{tabular}

En negrita: Bacterias que representan un alto riesgo de infección cruzada. 
de la Facultad de Odontología de la Universidad Shahid Sadoughi en Irán, el cual correspondió a 0-211 UFC, antes de realizar la desinfección de las superficies. Da Silva y col. (5) encontraron valores de 0-413 UFC y 0-81 UFC antes y después de proceder a la desinfección.

Mientras que en la investigación efectuada por Lee (6) y Arredondo (9) se hallaron de 0-2920 UFC y 0-286 UFC respectivamente, estos estudios difieren a las anteriormente mencionadas porque no realizaron análisis estadístico.

En los estudios efectuados por da Silva y col. (5), Lee (6), Ezoddini y col. (8), y Arredondo (9) se tomaron muestras del cuarto de revelado, en el presente estudio las muestras fueron tomadas de la caja de acrílico de revelado manual, similar al estudio de Freitas y col. (10).

Los altos valores encontrados se pueden explicar por el hecho de que las escuelas de odontología, en general, enseñan a los estudiantes los conocimientos teóricos necesarios en el control de infección, pero no proporcionan suficiente formación y estructura para su práctica, lo que desvaloriza la teoría enseñada.

Los resultados obtenidos en el presente estudio confirman el riesgo de contaminación por microorganismos a través de las superficies de los equipos radiográficos, como ya se ha demostrado en otros estudios $(5,6,8,9,10)$.

Los microorganismos que crecieron en las muestras recogidas, generalmente pertenecen a la flora ambiental normal y flora microbiana de los seres humanos y algunos se encuentran en la piel, cavidad bucal, vía respiratoria alta, aparato gastrointestinal y urogenital; sin embargo, pueden ser responsables de varias enfermedades. Las infecciones pueden desarrollarse cuando estos microorganismos son llevados a los sitios donde no se encuentran generalmente y los mecanismos de defensa del huésped no son capaces de restringirlos.

La alta prevalencia de Staphylococcus spp. sugiere la presencia humana por el hecho de que generalmente estas bacterias colonizan toda la superficie de los seres humanos. El $S$. aureus se ha convertido en uno de los patógenos nosocomiales de interés epidemiológico, ya que es el agente causante de diversas enfermedades con una elevada morbilidad y mortalidad. Esta bacteria representa el agente más común de las infecciones piógenas y pueden aislarse en casos de abscesos dentales, osteomielitis facial, faringitis y sinusitis $(11,12)$. Sin embargo, algunas especies se asocian con frecuencia a una gran variedad de infecciones de carácter oportunista. Las especies de Staphylococcus coagulasa negativos son consideradas en la actualidad como causa importante de infección, principalmente en pacientes inmunosuprimidos del medio hospitalario, como lo demuestra Marra y col. (13).

Asimismo, en lo referente a la alta frecuencia de bacilos gram negativos no fermentadores identificados en este estudio, principalmente Pseudomona spp., $P$. aeruginosa representa la especie de mayor importancia debido a que se ha observado que en las últimas décadas ha pasado a ser uno de los patógenos oportunistas más importantes en el medio hospitalario (14).

Otras bacterias significativas son Burkholderia cepacia y Acinetobacter baumannii, ambas son ubicuas y patógenas nosocomiales oportunistas en pacientes inmunosuprimidos. A. baumannii se encuentra raramente en piel humana $(0,5-3 \%)$ y heces humanas $(0,8 \%)(15,16)$. Además, se hallaron Enterobacter aglomerans y Klebsiella pneumoniae, ambas enterobacterias y patógenos oportunistas que suelen colonizar a pacientes hospitalizados. Esta última es la especie de mayor relevancia clínica dentro del género Klebsiella. Diversos estudios mencionan que estos patógenos hospitalarios son persistentes debido a su resistencia a múltiples antimicrobianos y desinfectantes (14).

Igualmente, se identificó Enterococcus faecalis, que forma parte de la flora gastrointestinal de humanos. Algunos estudios demuestran que esta bacteria se encuentra en infecciónes secundarias de los conductos radiculares obturados con periodontitis apical crónica y frecuentemente son aislados del canal radicular $(17,18)$. El E. faecalis es importante clínicamente ya que en años recientes se ha observado que emergen como una causa de infecciones nosocomiales oportunistas. Además, es capaz de sobrevivir en una serie de ambientes adversos permitiéndole múltiples vías de contaminación cruzada y producir infecciones en diferentes sitios del cuerpo (14).

En relación a la predominancia de las especies fúngicas en los equipos radiográficos, se encontró que había una 
mayor frecuencia de hongos filamentosos que levaduras, contrario a lo encontrado por Santos y col. (19) cuando evaluaron los equipos radiográficos en consultorios odontológicos de Teresina, Brasil. La Candida albicans fue la única levadura encontrada. Aunque la presencia de este hongo en la cavidad bucal es considerada como una condición normal de comensalismo, se le conoce como agente causante de diversas infecciones en pacientes inmunosuprimidos y está implicado en la periodontitis y la caries dental $(20,21)$.

En este estudio, Aspergillus flavus fue la especie que frecuentemente se halló. A. flavus y A. fumigatus son los hongos más comunes que habitualmente colonizan el tracto respiratorio y causan rinosinusitis e infecciones pulmonares. La aspergilosis invasiva de la cavidad bucal es poco común. Sin embargo, puede presentarse con mayor frecuencia en pacientes inmunocomprometidos con tumores malignos hematológicos, como lo demuestra Cho y col. (22) el año 2010, ellos describen un caso de un paciente con leucemia mieloide aguda que desarrolló una invasión localizada por A. flavus en el paladar.

Es importante resaltar que las demás especies bacterianas y fúngicas aisladas fueron de menor frecuencia en el presente estudio; aunque son raros los casos, pueden llegar a causar infecciones en diferentes partes del cuerpo.

La presencia de microorganismos como Streptococcus mutans, Eikenella corrodens, $C$. albicans sugiere que procedieron de la cavidad bucal, los cuales fueron transportados a las superficies radiográficas a partir de los guantes contaminados del operador. Asimismo, es probable que los microorganismos hayan sido trasladados de una superficie a otra por medio de los paños empleados durante el aseo de los ambientes clínicos por parte del personal de limpieza. Esto demuestra la posibilidad de contaminación cruzada durante la ejecución de los exámenes radiográficos, como también se ha demostrado en otros estudios $(1,3)$.

La contaminación de las superficies radiográficas es un problema difícil de resolver. La solución para este problema es mediante el empleo de soluciones desinfectantes o barreras protectoras en todas las superficies que van a ser contactadas, la mala utilización o el no utilizar estos métodos pueden crear un reservorio de microorganismos y resultar en una contaminación cruzada. Se recomienda el uso de desinfectantes aprobados por la ADA, como el hipoclorito de sodio, yodóforos y fenoles sintéticos.

La manga de la caja de revelado manual puede ser una fuente de contaminación cruzada si el operador utiliza guantes o películas contaminadas durante el revelado; por lo tanto, puede convertirse en un depósito para los agentes patógenos. El principal problema es la desinfección de la manga. Es por ello que, previamente al revelado, se recomienda desinfectar las películas radiográficas o los guantes empleados durante la toma radiográfica, emplear el método del doble guante o no utilizar guantes (23).

La Academia Americana de Radiología Oral y Maxilofacial sugiere que cada escuela de odontología desarrolle un método escrito para el control de infecciones cruzadas (24). El uso adecuado de un protocolo de control de infección puede reducir significativamente el número de microorganismos en las superficies y las soluciones de revelado.

Teniendo en cuenta los resultados de este estudio y otros estudios previos, es evidente la necesidad de mejorar el uso de métodos de barrera y evaluar las normas de limpieza y desinfección, de tal forma que pueda eliminarse o reducir la transmisión de microorganismos durante la ejecución de los exámenes radiográficos.

Es necesario que la institución desarrolle un protocolo de control de infecciones en los diferentes ambientes en donde se realiza la toma y revelado de radiografías dentales, así como la creación de un comité interdisciplinario compuesto por profesores, estudiantes y empleados para el control de infecciones en la Clínica Dental de la Facultad de Estomatología Roberto Beltrán.

Así mismo, se destaca la importancia de la actualización constante y el entrenamiento adecuado del personal de limpieza para aplicar los protocolos de desinfección más apropiados.

En conclusión, la presente investigación manifiesta la necesidad de desarrollar e implementar un nuevo protocolo de control de infección, el cual debe tener un monitoreo epidemiológico y de esta manera se tendrá un mejor control de infecciones durante la práctica radiográfica. 


\section{Correspondencia:}

\section{Luis Gustavo Paipay Santos}

Calle 57 Asoc. Casa Blanca Mz. N 1 Lote 5, San Juan de Lurigancho. Lima, Perú.

Correo electrónico: luis.paipay@upch.pe

\section{REFERENCIAS BIBLIOGRÁFICAS}

1. White SC, Glaze S. Interpatient microbiological crosscontamination after dental radiographic examination. J Am Dent Assoc. 1978; 96(5): 801-4.

2. Parks ET, Farman AG. Infection control for dental radiographic procedures in US dental hygiene programmes. Dentomaxillofac Radiol. 1992; 21(1):16-20.

3. Katz JO, Cottone JA, Hardman PK, Taylor S. Infection control in dental school radiology. J Dent Educ. 1989; 53(4):222-5.

4. American Dental Association Council on Scientific Affairs. The use of dental radiographs: update and recommendations. J Am Dent Assoc. 2006; 137(9):1304-12.

5. Da Silva M, Martins M, Medici E, Moraes L, Castilho J, Jorge A. Avaliação da eficiencia de um protocolo de controle de infecção em radiología odontológica, por análise microbiológica. Cienc Odontol Bras. 2004; 7(3):15-21.

6. Lee G. Determinación de la presencia de bacterias por medio de análisis microbiológico durante la práctica radiológica intraoral en el servicio de Radiología Oral y Maxilofacial de la Clínica Estomatológica Central de la Universidad Peruana Cayetano Heredia Tesis para optar el título de cirujano dentista. Lima, Perú. Universidad Peruana Cayetano Heredia, 2010.

7. Ministerio de Salud. Guía técnica para el análisis microbiológico de superficies en contacto con alimentos y bebidas. Act de 2007. Ley Pub ํ 26842. Lima, Perú: Diario El Peruano; 5 de junio del 2007.

8. Ezoddini F, Zandi H, Mohammadi Z, Ayatollahi J, Ayatollahi F, Behniafar B. Comparing the disinfecting efficacies of Micro 10, Deconex, Alprocid and Microzid $\mathrm{AF}$ on the microorganisms on radiographic equipments. JODDD. 2008; 2(2):48-52.

9. Arredondo D. Aplicación de métodos de asepsia y desinfección en la práctica de la radiología intraoral. Tesis de grado. Santiago de Chile, Chile: Universidad de Chile; 2006.

10. Freitas CV, Dias LC, Araujo CS, Da Silva VC, Monteiro-Neto V, Souza J. Assessment of microbiological contamination of radiographic devices in school of dentistry. Braz Dent Sci. 2012; 15(1):39-46.

11. Sydnor E, Perl T. Hospital epidemiology and infection control in acute-care settings. Clin Microbiol Rev. 2011; 24(1):141-73.
12. Cueva O, Cercenado E, Goyanes M, et al. Staphylococcuss sp. en España: Situación actual y evolución de la resistencia a antimicrobianos (19862006). Enferm Infecc Microbiol Clin. 2008; 26(5):269-77.

13. Marra A, Camargo L, Pignatari A, et al. Nosocomial bloodstream infections in Brazilian hospitals: analysis of 2563 cases from a prospective nationwide surveillance study. J Clin Microbiol. 2011; 49(5):1866-71.

14. Sydnor E, Perl T. Hospital epidemiology and infection control in acute-care settings. Clin Microbiol Rev. 2011; 24(1):141-73.

15. Miki R, Rubin L, Kirk J, Dodds S. Spontaneous septic arthritis caused by Burkholderia cepacia. Iowa Orthop J. 2006; 26:147-50.

16. Peleg A, Seifert H, Paterson D. Acinetobacter baumannii: emergence of a successful pathogen. Clin Microbiol Rev. 2008; 21(3):538-82.

17. Fisher K, Phillips C. The ecology, epidemiology and virulence of Enterococcus. Microbiology. 2009; 155(Pt 6):1749-57.

18. Salah R, Dar-Odeh N, Abu Hammad O, Shehabi A. Prevalence of putative virulence factors and antimicrobial susceptibility of Enterococcus faecalis isolates from patients with dental diseases. BMC Oral Health. 2008; 8:17. doi:10.1186/1472-6831-8-17.

19. Santos K, Movin M, Borba C, Noleto I. Isolamento de fungos de equipamentos radiográficos odontológicos. Rev Gaúcha Odontol. 2011; 59(3):411-16.

20. Pardi G, Cardozo E. Algunas consideraciones sobre Candida Albicans como agente etiológico de candidiasis bucal. Acta Odontol Venez (Internet) 2002; (Citada el 20 de julio del 2011); 40(1). Disponible en: http://www.actaodontologica.com/ediciones/2002/ 1/algunas_consideraciones_candida_albicans.asp.

21. Sifuentes J, Corzo D, Ponce de León L. Epidemiology of invasive fungal infection in Latin America. Curr Fungal Infect Rep. 2012; 6(1):23-34.

22. Cho H, Lee KH, Colquhoun AN, Evans SA. Invasive oral aspergillosis in a patient with acute myeloid leukaemia. Aust Dent J. 2010; 55(2):214-8.

23. Bartoloni JA, Charlton DG, Flint DJ. Infection control practices in dental radiology. Gen Dent. 2003; 51(3):264-72.

24. American Academy of Oral and Maxillofacial Radiology infection control guidelines for dental radiographic procedures. Oral Surg Oral Med Oral Pathol. 1992; 73(2):248-9.

Recibido: 05/11/2013

Aceptado: 20/02/2014 